Queda también la duda de si la figura por estar en Madrid pudiera corresponder al enterramiento proyectado por Gómez de Mora, pero el estilo no es definido para asignarlo a un artista concreto y por otra parte no se conoce, como se ha dicho, el escultor que llegó a realizar el sepulcro proyectado por dicho maestro.

Como datos a favor de la propuesta está la fecha del proyecto de Gómez de Mora, aunque pensamos que el arquitecto no hubiera propuesto una figura en madera, material poco usado, salvo en el sepulcro de los Barrionuevo en Fuentes (Guadalajara), donde la escultura principal de bronce de D. García obviaba el hacer unos enterramientos de categoría existiendo éste de San Ginés de Madrid ${ }^{21}$.

Además, y por último, quisiéramos destacar que las piezas de un Museo como el Valencia de D. Juan donde, como en otros muchos museos de sus características, no suele existir la documentación pertinente que pudiera permitir conocer su procedencia facilitando su clasificación.

Carmen Fernández AhiJAdo I.E.S. «Leandro Fernández de Moratín» Guadalajara

\title{
PEDRO DE CASTAÑEDA: SU PINTURA PARA EL REFECTORIO DEL COLEGIO MAYOR DE S. ILDEFONSO (1553)
}

El pintor Pedro de Castañeda es un artista poco conocido, activo en la zona de Alcalá de Henares en las décadas centrales del siglo xvi. Se sabe que junto a su hijo Juan fue colaborador del entallador y traductor de Vitruvio Miguel de Urrea. Pedro de Castañeda pintó un cirial que había tallado Urrea para la iglesia parroquial de Camarma de Esteruelas, trabajo por el que ambos cobraron cierta cantidad en 1540 , y en 1550 colaboró con ese entallador y con Claudio de Arciniega, ayudado por Juan, en la obra de los retablos colaterales de la iglesia de Daganzo de Arriba (perdidos), realizando su pintura. Parece que se trata del mismo artista el Pedro Castañeda que se documenta trabajando en la zona de Segovia, concretamente en dos retablos para la iglesia de Cascajares del Fresno. Falleció en $1557^{1}$.

Como es lógico, por tratarse de un pintor activo y con taller en Alcalá de Henares, Castañeda fue uno de los artistas del siglo xvi con los que podía contar la Universidad fundada por el Cardenal Cisneros en la villa complutense para las obras de pintura que la institución académica encargase, dado el caso. Tenemos una somera noticia que indica que un pintor llamado Castañeda, y que podemos identificar con el que nos ocupa, fue contratado para un trabajo auxiliar en la fábrica de la monumental fachada del Colegio Mayor de S. Ildefonso, que los colegiales decidieron levantar en 1537 y en obra hasta su inauguración en 1553, cuya construcción fue dirigida por Rodrigo Gil de Hontañón. Concretamente se pagaron el 12 de noviembre de 1544 «tres reales a Castañeda porque pintó dos figuras y dio de pintura a lo que el señor Rodrigo Gil había traça-

\footnotetext{
${ }^{21}$ M. Estella Marcos: «Problemas dela escultura cortesana de hacia 1600: Porres, el nacherino y otros». Real Palacio de El Escorial. Estudios inéditos del IV Centenario de la terminación de las obras. Departamento de Arte de I. Diego Velázquez, C.S.I.C. Madrid, 1987, pp. 221-240. M. ${ }^{a}$ C. Gracia Abad: El Señorío de Fuentes de la Alcarria, Guadalajara, 1994, pp. 192-196.

1 J. M. Cruz Valdovinos, «Miguel de Urrea, entallador de Alcalá y traductor de Vitruvio», Anales del Instituto de Estudios Madrileños, XVII, 1980, p. 69; M. A. Castillo Oreja, «La eclosión del Renacimiento: Madrid entre la tradición y la modernidad», en Madrid en el Renacimiento, Alcalá de Henares-Madrid, 1986, pp. 156-158; F. Collar de Cáceres, La pintura en la antigua Diócesis de Segovia (1500-1630), Segovia, 1989, p. 64; J. M. Cruz Valdovinos, «Retablos de los siglos xv y xvi en la Comunidad de Madrid», Retablos de la Comunidad de Madrid, Madrid, 1995, p. 44.
}

AEA, LXXVI, 2003, 303, pp. 301 a 329 
$d o »^{2}$, es decir, que diseñó o pintó cartones para los canteros de la obra, tanto de diseños arquitectónicos - probablemente detalles de las ventanas o alguna otra parte-, como de las figuras de los atlantes o los alabarderos de la planta noble del edificio colegial, sin que podamos especificar cuáles exactamente. Es posible, incluso, que a él se deba la plasmación en dibujos, previa al grabado, de la serie emblemática de la obra del recibimiento que la Universidad tributó al arzobispo de Toledo Juan Martínez Silíceo en 1546, titulada Publica Laetitia, qua Dominus Ioannes Martinus Silicaeus Archiepiscopus Toletanus ab Schola Complutensi susceptus est, impresa por Juan de Brocar el mismo año.

Nuestro desconocimiento de la obra y estilo de Pedro de Castañeda es total si exceptuamos su posible participación diseñadora en las figuras de la fachada que se citan, en el caso de los atlantes prácticamente perdida por su enorme grado de restauración. Este desconocimiento podrá verse parcialmente corregido con

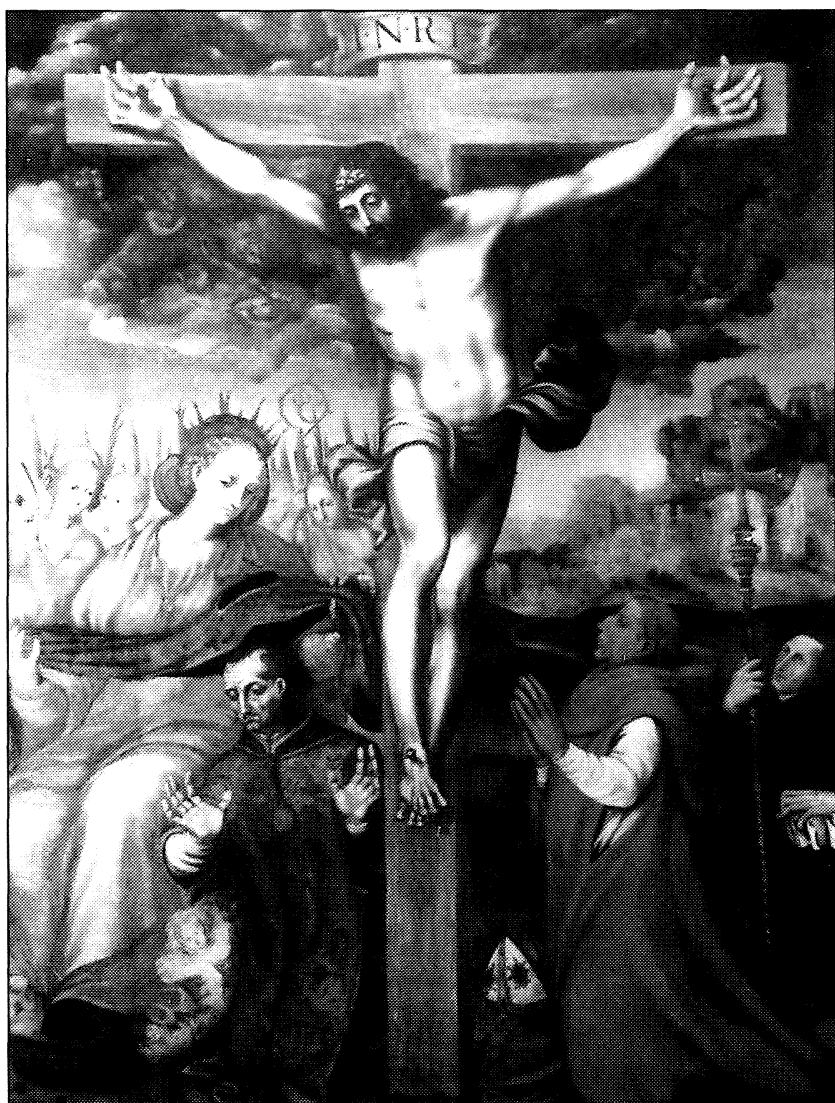

Pedro de Castañeda (1553): Cristo crucificado entre la Imposición de la casulla a S. Ildefonso y el Cardenal Cisneros orante acompañado de un acólito. Alcalá de Henares. Local social de la Sociedad de Condueños de los edificios que fueron Universidad. el descubrimiento que aportamos, una pintura de bastante gran tamaño que el pintor ejecutó para el mismo Colegio Mayor de S. Ildefonso Universidad de Alcalá.

El 15 de octubre de 1553 el tesorero del Colegio anotaba en su libro de cuentas el pago al pintor Pedro de Castañeda de 11.250 maravedís por el retablo que hacía poco había realizado para el refectorio del centro universitario ${ }^{3}$. La noticia aporta poco para poder conocer de qué tipo de obra se trataba o cuál era su iconografía, pero la información se complementa con la que aporta el acta de la capilla plena de rector y colegiales de S. Ildefonso (el órgano de gobierno colegiado de la institución) del 29 de noviembre de 1554, en la que se decidía que «En el Refitorio Se ponga una cortina En el crucifixo» ${ }^{4}$, que veremos que debía ser la obra realizada por el pintor. El 8 de junio del año siguiente Castañeda recibía la cantidad de 2.250 maravedís por haber hecho un escudo de armas del Cardenal Cisneros en dicho refectorio ${ }^{5}$, y el 27 de julio siguiente el tesorero del Colegio pagaba al maestro Calleja (un colegial) 1.564 maravedís por un velo y una vara de hierro $\left\langle p^{a}\right.$ El crucifixo del Refitorio» ${ }^{6}$, con lo que comprobamos que la de-

${ }^{2}$ J. D. Hoag, Rodrigo Gil de Hontañón. Gótico y Renacimiento en la arquitectura española del siglo xvı, Madrid, 1985, p. 109.

${ }^{3}$ Archivo Histórico Nacional (A.H.N.), sección Universidades, Libro 655, fol. 84 ro , cuentas del tesorero

${ }^{4}$ A.H.N, Universidades, Libro 1064, fol. $237 \mathrm{v}^{\mathrm{o}}$, actas de capillas plenas de rector y colegiales.

${ }^{5}$ A.H.N, Universidades, Libro 655 , fol. $88 \mathrm{v}^{\circ}$, cuentas del tesorero.

${ }^{6}$ Ibidem. Fol. 89 ro. 
cisión de la capilla se llevó a efecto. Todas estas someras noticias nos informan de: que Pedro de Castañeda realizó un retablo o cuadro con la representación de Cristo crucificado para el refectorio del Colegio Mayor complutense, que poco después se cubriría con una cortina sujeta por una barra de hierro; y que la decoración de dicha dependencia, situada desde la fundación de la Universidad hasta, al menos, finales del siglo xviII en la crujía occidental del patio principal colegial, y que había permanecido enormemente sobria, se complementaría con un cuadro con un escudo de armas de Cisneros y del propio Colegio Universidad.

Los inventarios de bienes muebles del Colegio Mayor complutense incluyen registros de los del refectorio desde bastante pronto, pero hasta el redactado en 1653 no encontramos mención a decoración alguna, registrándose en ellos exclusivamente la vajilla de plata y la mantelería, entre otros objetos. Sin embargo en el inventario citado de 1653 aparece una partida dedicada precisamente a «Un quadro de un $S^{t o}$. christo con su marco» ${ }^{7}$. Hemos podido constatar que ninguna obra de esas características se contrató o adquirió para S. Ildefonso con posterioridad al encargo a Castañeda, y el hecho de que hasta ese año no se hubiese registrado no debe llevarnos a engaño, pues los inventarios del refectorio tenían como misión únicamente evitar la desaparición de los bienes puestos bajo la responsabilidad del refitolero, entre los que no se encontraban en principio los cuadros de ese recinto. Desde entonces hasta 1797, cuando consta por última vez la existencia de ese ámbito con su función original, la obra se registró sin solución de continuidad descrita como cuadro de pintura, con marco negro, dorado o negro y dorado, situado en uno de los testeros de la sala, como Santo Cristo, crucifijo o efigie de Jesucristo, etc..., salvo en una ocasión. El inventario del refectorio de 1729 concreta que se trataba de «Un quadro de Un Santo Christo y a los pies nro santo Amo Pintado en Lienzo y Con Marco Negro que esta en la Testera de el refectorio» ${ }^{8}$, es decir, un Crucificado con el Cardenal Cisneros - el Santo Amo, como se le denominaba en el Colegio por entonces- a sus pies.

Tras la desaparición de la Universidad de Alcalá y una primera venta de sus edificios, se creó (1850) una sociedad de copropietarios que los adquirió y hasta hoy los ha gestionado, llamada Sociedad de Condueños ${ }^{9}$. Esta Sociedad posee, en su local social alcalaíno, un gran lienzo $\left(152 \times 204 \mathrm{~cm}\right.$.), pegado en una tabla y que ha sido recientemente restaurado ${ }^{10}$, que presenta, en un estilo muy propio de mediados del siglo xvI, la representación de un Cristo crucificado flanqueado por sendas imágenes a la altura del nivel del suelo. La de la izquierda representa la Imposición de la casulla a S. Ildefonso, y la de la derecha al Cardenal Cisneros que, arrodillado, reza al Salvador. La Imposición de la casulla tiene como protagonista a la Virgen, tras la que se disponen las santas mártires con sus palmas, imponiendo la casulla a S. Ildefonso, tema que, además del motivo heráldico de la catedral de Toledo, es el más usualmente representado episodio de la vida del santo patrono del Colegio Universidad. Al otro lado de la Cruz, como de-

\footnotetext{
${ }^{7}$ A.H.N, Universidades, Libro 682, folio $146 \mathrm{v}^{\circ}$, inventarios de bienes muebles.

${ }^{8}$ A.H.N, Universidades, Libro 683, folio $66 \mathrm{r}^{\circ}$, inventarios de bienes muebles.

${ }^{9}$ Véanse: L. Acosta de la Torre, Guía del viajero en Alcalá de Henares, Alcalá de Henares, 1882, p. 136-137; V. de la Fuente, Historia de las Universidades, Colegios y demás establecimientos de enseñanza en España, Madrid, 1889, IV, pp. 430 431; H. Castro, Guía ilustrada histórico-descriptiva de Alcalá de Henares, Alcalá de Henares, 1929, pp. 34-35; A. Marchamalo Sánchez y M. Marchamalo Maín, El sepulcro del Cardenal Cisneros, Alcalá de Henares-Madrid, 1985, pp. 82-85; F. J. García Gutiérrez, La Sociedad de Condueños, Alcalá de Henares, 1986; A. Marchamalo Sánchez, «La venta del Colegio Mayor de San Ildefonso en 1845. Notas para la historia de un expolio», Actas del II Encuentro de Historiadores del Valle del Henares, Alcalá de Henares, 1990, pp. 543-549; J. Fernández Majolero, Breve Historia de la Sociedad de Condueños, Alcalá de Henares, 2000; J. F. Huerta Velayos, La Sociedad de Condueños: una historia compartida, Alcalá de Henares, 2000.

${ }^{10}$ Sobre la restauración de la pintura puede verse Sociedad de Condueños de los Edificios que fueron Universidad. Memoria correspondiente al Ejercicio de 1998, Alcalá de Henares, 1998, pp. 19-20. Últimamente se ha expuesto -sin aparecer en el catálogo- en la exposición Cisneros y el Siglo de Oro de la Universidad de Alcalá, Alcalá de Henares, abriljulio de 1999, y en la que tuvo lugar en la capilla del Oidor de Alcalá de Henares —reproducida la pintura en su catálogo- entre diciembre de 2000 y enero de 2001: cfr. VV. AA., La Sociedad de Condueños: una historia compartida, Alcalá de Henares, 2000, pp. 42-43.
}

AEA, LXXVI, 2003, 303, pp. 301 a 329 
cíamos, encontramos la figura del Cardenal Cisneros, inequívocamente individuado por su perfil, tomado seguramente del paradigmático retrato marmóreo que era propiedad del Colegio desde 1518 y que hoy conserva la Universidad Complutense de Madrid. Arrodillado y con las manos juntas en actitud orante, va vestido de cardenal, con la mitra de arzobispo y el capelo depositados en el suelo ante él. Tras su figura hay otra, vestida con manto y de negro - quizás de pardo y negro-, que sostiene la cruz arzobispal con una mano y un libro con la otra. Sobre los dos, a lo lejos, una esquemática representación de Jerusalén muestra entre sus edificios una estructura de planta central flanqueada por media exedra, que debe haberse tomado de algún grabado de un tratado de arquitectura de la época. Sobre la figura de Cristo se despliega un conjunto de nubes tormentosas pobladas de angelotes, definidos como putti renacentistas.

Estilísticamente muestra importantes referencias a la pintura nórdica, flamenca, pero también alemana - recuerda enormemente crucificados de Durero o Lucas Cranach-, con evidentes detalles de expresividad patentes en la factura de las manos del Crucificado y S. Ildefonso, en sus rostros y otros detalles de gran fuerza - y relativa corrección en cuanto a proporciones-. El paño de pureza al viento recuerda enormemente modelos primitivos flamencos, de expresiva emotividad.

La disposición de Cisneros y su acólito remiten también inmediatamente a la de los donantes típicos de la pintura flamenca del siglo xv ${ }^{11}$. Si el Cardenal aparece en el lugar principal, y podemos interpretar su posición de donante como la personificación de la propia Universidad, su acompañante en segundo plano bien pudiera ser uno de los representantes de la autoridad de aquélla. Su rostro está lo suficientemente individualizado como para que podamos ver en él la figura del cancelario o, lo que parece más probable por su juventud, del propio rector, pero no queda del todo claro si viste el manto colegial - aunque parece que lleva muceta negra-. Si se tratase del rector, sería Diego de Entrena (curso 1552-53).

Por otro lado, además de las ya referidas alusiones a la estética del Renacimiento en la estructura arquitectónica y los angelitos citados, es evidente que el conjunto que forman las figuras de la Imposición de la casulla está tomado de la pintura romanista contemporánea, quizás anterior, con evidentes referencias rafaelescas y manieristas. La figura de la Virgen se ha definido como una matrona vestida a la antigua, realizada de manera que nos remite a algún tipo de grabado o dibujo italiano, casi de la misma forma que las representaciones de alegorías.

Todo lo visto anteriormente indica que, con la mayor probabilidad, se trata del «retablo» pintado por Pedro de Castañeda en 1553, que habría sido trasladado por la citada Sociedad de Condueños desde su secular ubicación a su local social en fecha indeterminada de los siglos XIX y Xx. La obra fue realizada, y seguramente encargada, ese año, el mismo de la inauguración de la monumental fachada del Colegio Mayor, por lo que es muy probable que su encargo tenga relación no sólo con este hecho, sino con el mismo significado de la fachada cuando se proyectó, antes de verse desvirtuada en su pureza de líneas por la elocuente iconografía heráldica estatal, la de revindicar la autonomía universitaria, tan amenazada por las actuaciones a lo largo de la primera mitad del Quinientos por parte de los arzobispos de Toledo (Fonseca, Tavera, Silíceo), y que la institución académica se veía poco a poco obligada a ceder a su máxima valedora y protectora, la Monarquía ${ }^{12}$.

ROBERTo GonZÁLeZ RAMOS Universidad de Córdoba

\footnotetext{
"Sobre la figura del donante en la pintura española del siglo xvi, su evolución, formas y significados, véase M. A. Raquejo Grado, «El donante en la pintura española del siglo xvi. Su ubicación en el espacio ficticio», Goya, 164-165, 1981, pp. 76-87.

${ }^{12}$ Sobre la influencia de la lucha de la Universidad por mantener su independencia en la definición formal de la fachada del Colegio Mayor véase F. Marías, «Orden arquitectónico y autonomía universitaria: la fachada de la Universidad de $\mathrm{Al}$ calá de Henares y Luis de Vega», Goya, 217-218, 1990, pp. 28-40.
}

AEA, LXXVI, 2003, 303, pp. 301 a 329 